\title{
Effect of Surface Condition of Electrode on the Surface Melting of Material by Laser-Guided Micro-Arc Discharge
}

\author{
Wang Zhitong, Zhan Jian, and Yang Mingjiang
}

\begin{abstract}
This paper studies the surface melting in the atmosphere by YAG laser-guided micro-arc discharge. In three kinds of surface conditions (free, oiled, and polyethylene covered), we try to control the diameter and the power density of discharge pit. It is found that the power density of $3 \times 10^{6} \mathrm{~W} / \mathrm{cm}^{2}$ of discharge pit on the oiled surface is moderate to form the melted layer thicker than that of the others, adapting to strengthen the surface of material, and the power density of $1.07 \times 10^{7} \mathrm{~W} / \mathrm{cm}^{2}$ of discharge pit on the polyethylene-covered surface is highest to form the deepest discharge pit among them, adapting to remove the material.
\end{abstract}

Index Terms - Laser-guided micro discharge, surface condition of electrode, surface melting.

\section{INTRODUCTION}

$\mathbf{N}$ OWADAYS, many people study the mechanism of laser plasma guiding discharge [1], [2] and succeed some studies of laser-guided lightning and laser-guided discharge (LGD) at long distance of atmosphere [3], [4]. It was also reported that the LGD was applied to processing. For example, Gilgenbach et al. [5] performed the LGD boring in aluminum foil in the atmosphere by $\mathrm{CO}_{2}$ laser, Hoshi et al. [6], [7] studied the LGD marking and processing inside of workpiece at low air pressure by 532-nm YAG laser, and we have also succeeded the similar study in electrode gap of less than $1-\mathrm{mm}$ by $1.06-\mu \mathrm{m}$ YAG laser [8], [9].

It is important that the strengthening of material surface may improve the performance of frictional surface and increase the lifetime of frictional surface. In processing, the disperse processing is better than the covering processing. The disperse strengthening point not only increases the lifetime of frictional surface but also avoids the processing crack in covering strengthening. The laser-guided micro-arc discharge has the following two main merits as a kind of new method of surface strengthening: 1) the controllable position of discharge pit-by laser guiding, the position of discharge pit may be placed according to the need of frictional performance, and 2) the controllable shape of discharge pit—by laser guiding, the shape

Manuscript received March 11, 2008; revised June 6, 2008. Current version published November 14, 2008. This work was supported by the National Natural Science Fund of China (60877064).

The authors are with the Division of Technology Sciences, Institute of Mechanics, Chinese Academy of Sciences, Beijing 100080, China.

Digital Object Identifier 10.1109/TPS.2008.2002033 of discharge pit is like round or ellipse, so we can easily adjust the power density of discharge pit by controlling the diameter of discharge pit.

This paper studied the effect of three kinds of surface conditions (free, oiled, and polyethylene covered) of electrode on the surface melting by laser-guided micro-arc discharge, including the property of discharge channel, the morphology of discharge pit, and so on.

\section{PRINCIPLE AND EQUiPMENT}

In Fig. 1, the experimental schematic is shown. The YAG laser equipment was worked by single shot, with $15-\mathrm{mJ}$ pulse energy, 120-ns pulsewidth, and 1.06- $\mu \mathrm{m}$ wavelength. A copper stick with pin head was the cathode. The stick was tilted enough close to the metal plasma but not to shelter from the laser. A cylinder of nodular cast iron was used for the anode, and the surface of the cylinder was strengthened in the experiment. The laser was focused on the surface of the cylinder by the lens; the diameter of focus was about $150 \mu \mathrm{m}$. In order to acquire the better shape of discharge pit, the impress was just applied before the laser pulse, and the position of the cathode was carefully adjusted. The initial discharge voltage was $400 \mathrm{~V}$, the gap of electrode was $0.5 \mathrm{~mm}$, and the triggering probability was $100 \%$. The pulsewidths were always designed as $100 \mu \mathrm{s}$, and the pulse energy was all assured as $1 \mathrm{~J}$ by adjusting the voltage. As the continued-current diode was used in voltage supply, the current will be maintained through it to result in the appreciably different pulsewidths of different surface conditions after the impress ended. The probes of voltage and current were worked in circuit, and the waveforms were stored to the oscillograph Tektronix TDS210.

The experiment was performed in the atmosphere. The oil film was laid beforehand on the surface of the cylinder, and the polyethylene film was also pasted beforehand. The thickness of all the films was about $0.1 \mathrm{~mm}$. The surface photographs of discharge pit were taken by the tridimensional microscope Olympus SXZ12, and the samples of cross section were prepared and photographed. When the samples of cross section were prepared, the three kinds of discharge pits were compactly aligned to place themselves on one sample of cross section. Accordingly, even if the sample was departed from the center line of discharge pit in the prepared process, the relative shape of cross sections of the three pits was unchangeable; the error of data was less. 


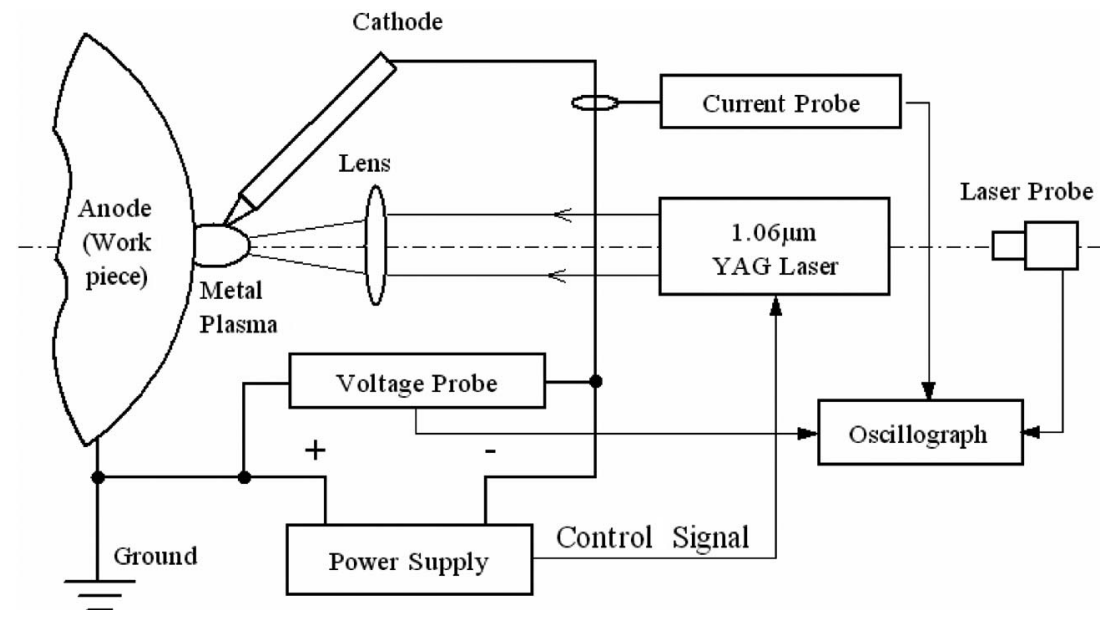

Fig. 1. Schematic of surface melting of material by laser-guided micro-arc discharge.

TABLE I

DiAMETERS OF DischaRge PIT

\begin{tabular}{|c|c|c|c|}
\hline \multirow{2}{*}{ No. } & \multicolumn{3}{|c|}{ Diameters of discharge pit } \\
\cline { 2 - 4 } & Free Surface & Oiled Surface & polyethylene Covered Surface \\
\hline 1 & 949 & 609 & 378 \\
\hline 2 & 909 & 618 & 433 \\
\hline 3 & 992 & 650 & 423 \\
\hline Mean & 950 & 626 & 411 \\
\hline
\end{tabular}

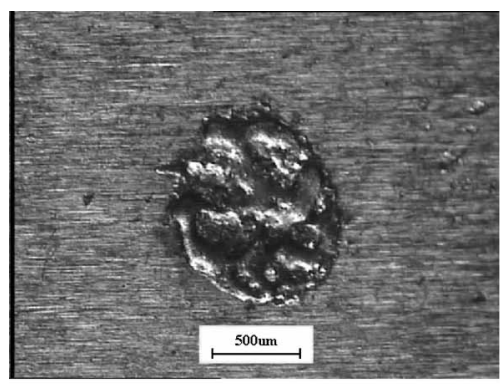

(a)

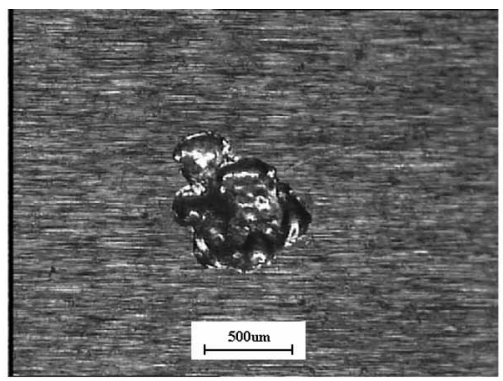

(b)

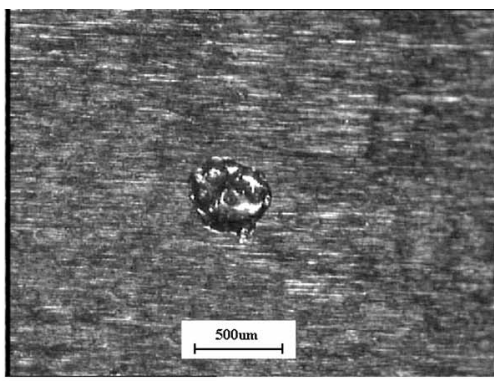

(c)

Fig. 2. Surface morphology of discharge pit. (a) Free surface. (b) Oiled surface. (c) Polyethylene-covered surface.

\section{RESULTS AND DiscUSSION}

\section{A. Effect of Surface Condition on Micro-Arc Discharge Channel}

According to the experimental schematic, the experiment of LGD was performed in three kinds of surface conditions. The diameters of discharge pits were measured, and the data are shown in Table I. It is obvious that the discharge pits are less on the oiled and polyethylene-covered surfaces than that on the free surface, and the discharge pit on the polyethylenecovered surface is least among them. The surface photographs of first group data in Table I are shown in Fig. 2. The appearances of discharge pit are comparatively regular like an ellipse, and there is no separately small discharge pit around the main discharge pit. The voltage and current waveforms of discharge pit in Fig. 2 are shown in Fig. 3. The waveforms of the free surface are almost the same as those of the oiled surface, and the waveform of the polyethylene-covered surface is obviously different from the others. The rise times of the current waveform in Fig. 3(a) and (b) are almost the same as $12 \mu \mathrm{s}$, but their decline times are quite different. The decline time in Fig. 3(a) lasts for $100 \mu$ s, but that in Fig. 3(b) is only $20 \mu \mathrm{s}$. The drop of decline times of the current waveform indicates that the continuous-flowing capability of micro-arc is low, so the micro-arc will rapidly die after the voltage supply is off. Now, we begin to consider the resistance of the micro-arc. The arc voltage of Fig. 3(a) is $30 \mathrm{~V}$, whereas that of Fig. 3(b) is $100 \mathrm{~V}$. The current of Fig. 3(a) is $300 \mathrm{~A}$, whereas that of Fig. 3(b) is 120 A. As a result, the resistance of Fig. 3(a) is $0.1 \Omega$, and that of Fig. 3(b) increases to $0.8 \Omega$. It is the reason of the drop of the continuous-flowing capability of the arc, in which increasing the arc resistance will quicken the consumption of the energy stored in the circuit after the voltage supply is turned off. 


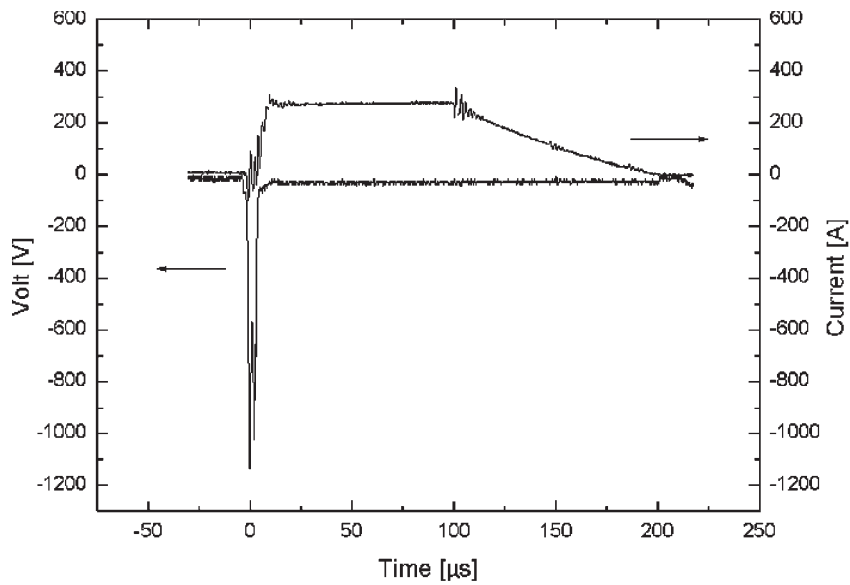

(a)

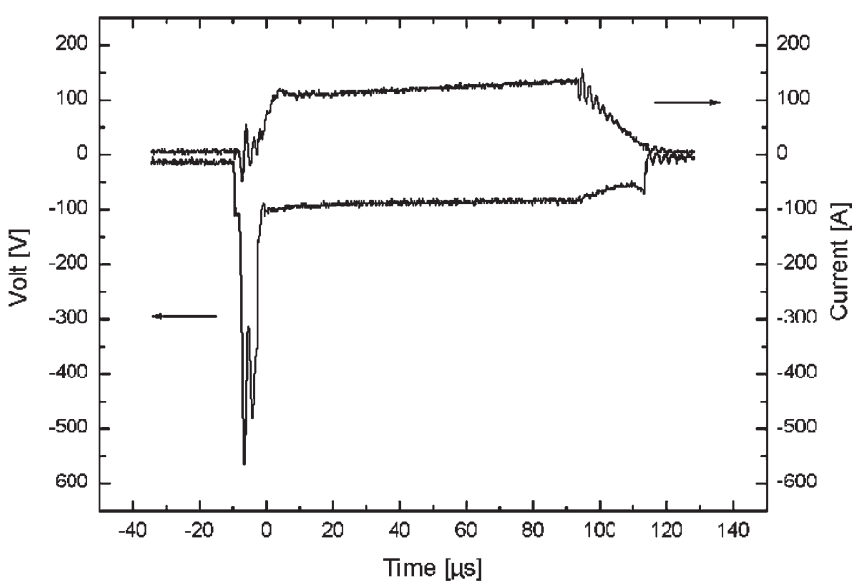

(b)

Fig. 3. Voltage waveform and current waveform. (a) Free surface and oiled surface. (b) Polyethylene-covered surface.

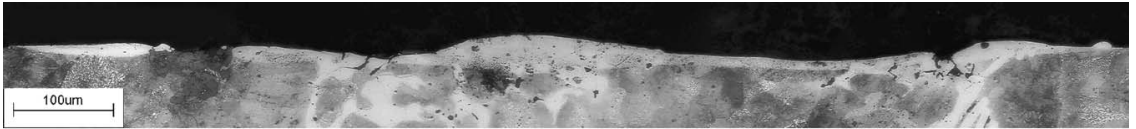

(a)

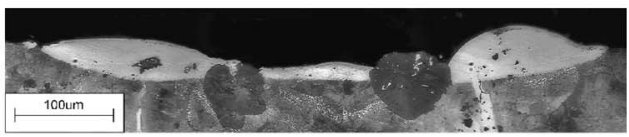

(b)

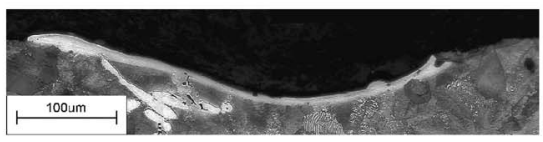

(c)

Fig. 4. Photographs of cross section of discharge pit. (a) Free surface. (b) Oiled surface. (c) Polyethylene-covered surface.

\section{B. Effect of Surface Condition on the Morphology of Discharge Pit}

The samples of cross section of discharge pit shown in Fig. 2 were prepared, and the photographs are shown in Fig. 4. In Fig. 4, the white part near the surface of material is the melted layer, and the big block of black ball is the unmelted graphite. The discharge pit on the polyethylene-covered surface is formed with a depth of about $70 \mu \mathrm{m}$, and its melted layer is thinnest among them. The discharge pit on the oiled and free surfaces were formed with the thicker melted layer than that on the polyethylene-covered surface, and the melted layer of discharge pit on the oiled surface is thicker than that on the free surface. The morphology of discharge pit on the free surface is flattest among them.

\section{Cooling Usage of Surface Film in Discharge Pit}

In Fig. 5, the usage of surface film in LGD is shown. While the discharge pit expands, the film on the surface is burned off. The consumed energy of the film will cool the discharge pit to limit the increase in diameter of discharge pit. The vaporized heat of the polyethylene film is about $400 \mathrm{~kJ} / \mathrm{kg}$ [10] higher

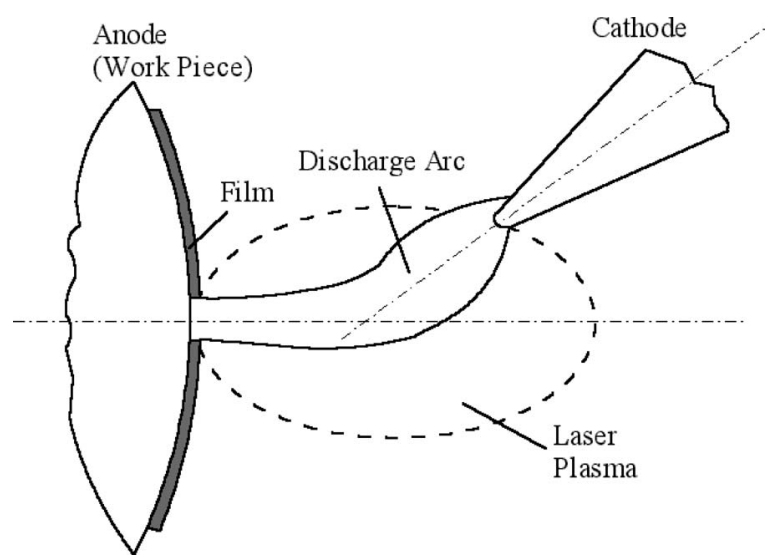

Fig. 5. Schematic of the usage of surface film in laser-guided discharge.

than the $220 \mathrm{~kJ} / \mathrm{kg}$ [11] of the oil film, so the polyethylene film needs more energy to burn off than the oil film. Because the expansion of discharge pit on the polyethylene-covered surface needs to consume the most energy among the three kinds of surface conditions, the least discharge pit is acquired, the next is on the oiled surface, the last is on the free surface. 


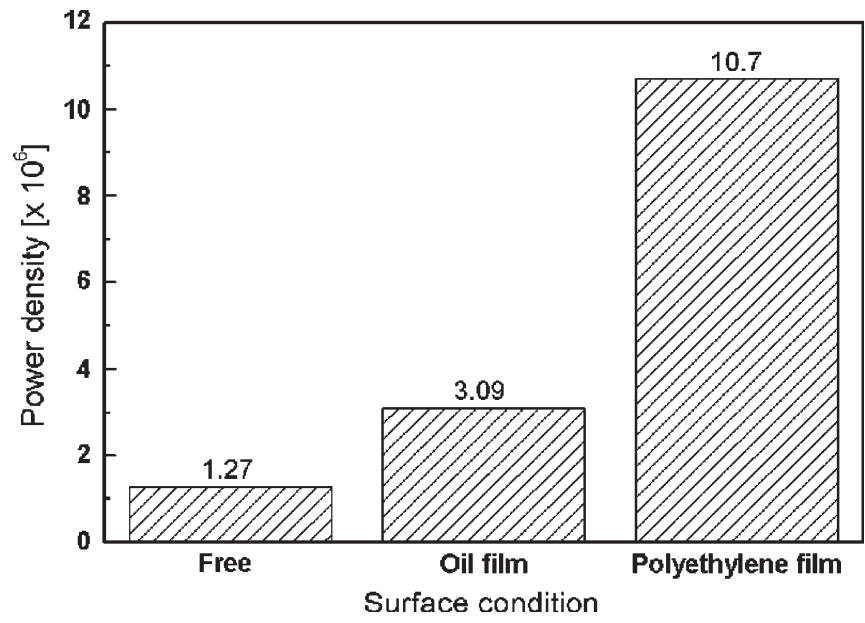

Fig. 6. Comparison of power density of discharge pit in three kinds of surface conditions.

\section{Effect of Surface Film on the Power Density and Morphology of Discharge Pit}

In the experiment, we use the same energy $(1 \mathrm{~J})$ in three kinds of surface conditions, and the diameters of discharge pits and the pulsewidths of discharge are also measured and shown in Table I; as a result, the mean power densities of discharge pit may be calculated and shown in Fig. 6. It is obvious that the power density on the free surface is lowest; that on the polyethylene-covered surface is higher a grade than that on the free surface, which reaches $10^{7} \mathrm{~W} / \mathrm{cm}^{2}$. The power density which on the oiled surface is moderate among them is 2.4 times higher than that on the free surface. Based on the photographs of Fig. 4, we think that the power density on the oiled surface is optimum to strengthen the surface of material, because the micro-arc sufficiently melt the surface without serious splash, and the melted layer of discharge pit is thickest. The power density of discharge pit on the polyethylene-covered surface is so high that the melted layer of material is shot off to form the deepest discharge pit.

\section{CONCLUSION}

The film covered on the surface of electrode may cool the discharge pit, limit the increase of discharge pit, control the power density of discharge pit, and affect the surface morphology of discharge pit. For nodular cast iron, when the oil film is covered on the surface of electrode, the power density of discharge pit is about $3.09 \times 10^{6} \mathrm{~W} / \mathrm{cm}^{2}$, the surface of electrode is sufficiently melted, and the splash of the melted layer is little, adapting to strengthen the surface of material. When the surface of electrode is free, the power density of discharge pit is $1.27 \times 10^{6} \mathrm{~W} / \mathrm{cm}^{2}$, the surface just melts, and the thickness of the melted layer is less than that of the oiled surface. After the polyethylene film is pasted on the surface of electrode, the power density of discharge pit increases to $10^{7} \mathrm{~W} / \mathrm{cm}^{2}$, the splash of the melted layer is serious, so the discharge pit is deepest, and the remains of the melted layer is little, adapting to remove the material.

\section{REFERENCES}

[1] D. W. Koopman and K. A. Saum, "Formation and guiding of high-velocity electrical streamers by laser-induced ionization," J. Appl. Phys., vol. 44, no. 12 , pp. 5328-5336, Dec. 1973.

[2] Y. Hoshi, H. Yoshida, K. Yamanaka, and Y. Usui, "Time delay in laserguided discharge at low air pressure," IEEE Trans. Plasma Sci., vol. 24, no. 3, pp. 1137-1146, Jun. 1996.

[3] T. Shindo, Y. Aihara, M. Miki, and T. Suzuki, "Model experiments of laser-triggered lightning," IEEE Trans. Power Del., vol. 8, no. 1, pp. 311317, Jan. 1993

[4] A. Desparois and B. L. Fontaine et al., "Study of laser-induced breakdown in a 30-cm air gap under a uniform field," IEEE Trans. Plasma Sci., vol. 28 , no. 5, pp. 1755-1762, Oct. 2000.

[5] R. M. Gilgenbach, O. E. Ulrich, and L. D. Horton, "Localized metallic melting and hole boring by laser guided discharges," Amer. Inst. Phys., vol. 54, no. 1, pp. 109-113, Jan. 1983.

[6] Y. Hoshi and H. Yoshida, "Application of laser-guided discharge to processing," Appl. Phys. A, Mater. Sci. Process., vol. 68, no. 1, pp. 93 98, Aug. 1999.

[7] Y. Hoshi, H. Yoshida, and Y. Tsutsui, "Electric discharge image marking using laser guided discharge," IEEE Trans. Plasma Sci., vol. 28, no. 5, pp. 1771-1774, Oct. 2000.

[8] W. Zhitong and Y. Mingjiang, "The experimental study of delay time discharge in laser guiding discharge machine," Laser J., vol. 23, pp. 29 32, Feb. 2002. (in Chinese).

[9] W. Zhitong and Y. Mingjiang, "The experimental study of laser guiding discharge boring hole," Appl. Laser, vol. 22, pp. 2-6, Feb. 2002. (in Chinese).

[10] Q. Yinghong, Su Liao Shou Ce. Beijing, China: Eng. Ind., 1991. (in Chinese).

[11] L. Shupei, Shi You Jia Gong Gong Yi Xue. Beijing, China: Petrochemical, 2007. (in Chinese).

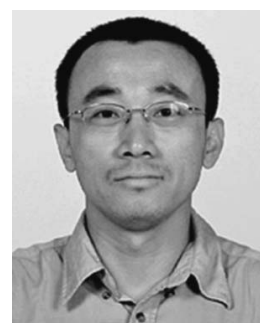

Wang Zhitong was born in China in $1972 . \mathrm{He}$ received the Ph.D. degree from the Institute of Mechanics, Chinese Academy of Sciences, Beijing, China.

$\mathrm{He}$ is currently with the Division of Technology Sciences, Institute of Mechanics, Chinese Academy of Sciences. His main research work is about laser surface modification. He has recently been studying the strengthening of material surface by laser-guided discharge in the atmosphere.

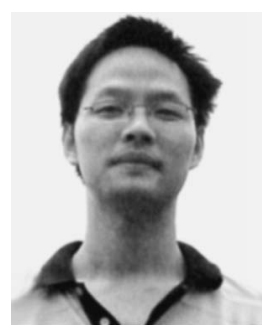

Zhan Jian was born in China in 1981. He is currently working toward the Ph.D. degree with the Chinese Academy of Sciences, Beijing, China. His major is about the strengthening of material surface by laser-guided discharge in the atmosphere.

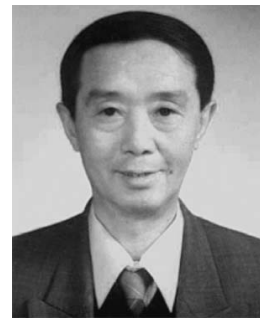

Yang Mingjiang was born in China in 1944. He received the Ph.D. degree from the Chinese Academy of Sciences, Beijing, China.

$\mathrm{He}$ is currently with the Division of Technology Sciences, Institute of Mechanics, Chinese Academy of Sciences. He is a Chief of the National Center for Laser-Texturing Technology Development and Application. He improved the technique of YAG laser texturing, and applied this technique to the cold-roll industry. 